\title{
Técnica para aislamiento de bacteriófagos específicos para E.coli DH5a a partir de aguas residuales
}

\author{
Bacteriophages specific for DH5a strain of $E$. Coli from wastewater \\ isolation techniques
}

\author{
Gabriel Gaviria A, ${ }^{1}$ Biól, María González de S, ${ }^{1}$ M.Sc, Jhon Castaño O, ${ }^{1 *}$ Ph.D.
}

\begin{abstract}
1Universidad del Quindío. Facultad Ciencias de la Salud. Centro de Investigaciones Biomédicas. Grupo de Inmunología Molecular (GYMOL). Carrera 15 Calle 12 Norte, Teléfono: $+57(6)$ 7460168. Armenia, Colombia. *Correspondencia: jhoncarlos@uniquindio.edu.co
\end{abstract}

Recibido: Septiembre de 2010; Aceptado: Junio de 2011.

\section{RESUMEN}

Objetivo. Establecer una técnica para el aislamiento de bacteriófagos a partir de aguas residuales específicos para E. coli DH5a. Materiales y métodos. Se tomó como base el método 1601 de la Agencia de Protección Ambiental de los Estados Unidos de América y un método de obtención de enterovirus a partir de aguas residuales. En el desarrollo del protocolo se realizaron múltiples pruebas utilizando como control positivo el bacteriófago T4 y los aislamientos de bacteriófagos obtenidos a partir de aguas residuales. Resultados. Se observó la formación de unidades formadoras de placa (UFP), se obtuvó la titulación de los bacteriófagos presentes en cada uno de los cultivos de E.coli DH5a, se determinaron las relaciones que existen entre la cuantificación de la formación de unidades formadoras de placa (UFP) del tratamiento control y el tratamiento experimental y las respectivas características de las (UFP) en cada uno de los experimentos realizados. Conclusiones. Se logró establecer un protocolo microbiológico para el aislamiento de bacteriófagos específicos para $E$. coli DH5a.

Palabras clave: Aislamiento, bacteriófagos, E. coli (Fuente: $C A B)$.

\begin{abstract}
Objetive. To develop an isolation technique for DH5a E. coli specific bacteriophages in wastewater. Materials and methods. The 1601 method of the Environmental Protection Agency of the United States of America and an wastewater enterovirus obtaining method were used as a reference. During the development of the protocol, multiple tests were performed using the T4 bacteriophage as positive control and the bacteriophage isolates obtained from wastewater. Results. Plaque-forming units (PFU) were observed; tittering of bacteriophages present in each of the DH5a $E$. coli cultures was obtained; the relationships between the quantification of PFU in the control and experimental groups, and their corresponding PFU characteristics were determined for each of the experiments. Conclusions. It was possible to establish a microbiological protocol for the isolation of bacteriophages specific for DH5a E. coli.
\end{abstract}

Key words: Bacteriophage, isolation, E. coli (Source: $C A B$ ). 


\section{INTRODUCCIÓN}

Los bacteriófagos son virus que fueron descubiertos de forma independiente por los microbiólogos Frederick W. Twort (1) en 1915 y Félix d'Hérelle (2) en 1917. Siendo esta la última clase principal de virus en ser descubierta; este tipo de virus constituye un sistema simple y de gran abundancia en la naturaleza. En esencia, los bacteriófagos se encuentran de manera ubicua en el ambiente y en el lugar en que se encuentre su célula huésped (3).

Los bacteriófagos son virus que infectan y se multiplican en la bacteria, llevando a la destrucción la célula hospedera con la liberación de bacteriófagos que re-infectan otras bacterias. Los bacteriófagos fueron descubiertos en las primeras décadas del siglo $\mathrm{XX}$, pero su uso clínico no se extendió en países occidentales sino hasta la década del 80 , debido a diferentes razones. A pesar de que se realizaron múltiples esfuerzos para generalizar su uso como agentes terapéuticos en las décadas de 1920 y 1930 fueron cayendo en el olvido por la ciencia de la época debido al descubrimiento de los antibióticos.

Un papel muy importante jugó la Asociación Médica Americana, la cual recomendó que se debía dejar todo tipo de tratamiento a través de bacteriófagos. Este rechazo se dio por razones como el desconocimiento de la biología de los bacteriófagos para ese entonces, el diseño erróneo de los protocolos experimentales y la falta de controles adecuados en los diferentes experimentos realizados (2). Además, con el empleo generalizado de los antibióticos para combatir infecciones, durante casi cuarenta años se abandonó en occidente cualquier tipo de investigación sobre el uso de bacteriófagos como agentes terapéuticos, aunque se usaron de forma extensa para análisis genéticos y para establecer las bases de la biología molecular. Posteriormente, para la década de 1980, de nuevo se empezaron a usar los bacteriófagos en animales de experimentación en los países occidentales. En este sentido, los trabajos de Smith y Huggins (4) en la década del 80 se pueden considerar como un punto de inflexión, al retomar de nuevo la importancia de los bacteriófagos en la terapia animal, ya que de estos se habían obtenido resultados muy esperanzadores.

Los bacteriófagos se componen de un solo tipo de ácido nucleico (ARN o ADN) encapsulado por una cubierta proteica que exhibe los elementos estructurales necesarios para una infección específica (5). Algunos presentan una envoltura lipídica que se deriva de la célula hospedera. La conformación y organización proteica de sus cápsides les confiere la habilidad de permanecer viables por largos períodos de tiempo en el ambiente en condiciones adversas, como la exposición a ADN-asas, variaciones de $\mathrm{pH}$ y temperatura (6). Los bacteriófagos han sido tomados como modelo para el estudio de la genética bacteriana y los mecanismos de control de la expresión génica, debido a que los hospederos bacterianos son fácilmente cultivables y manejables en el laboratorio (7).

Los bacteriófagos, entre otras utilidades dentro de las ya conocidas, sirven como herramienta para la modificación genómica bacteriana y para la construcción de vacunas a nivel terapéutico. Además, en terapias alternativas, para el tratamiento de infecciones producidas por bacterias; dicha utilidad es sustentada por investigadores y científicos a través de estudios rigurosos, donde se han aislado bacteriófagos y posterior a esto se han caracterizado de forma específica, siendo utilizados respectivamente de acuerdo con el interés investigativo. Algunos de estos trabajos han sido realizados por varios autores (7-17). Debido a la adaptación de patógenos multirresistentes a los antibióticos se están retomando los estudios sobre fagoterapia $(7,18)$.

Se consideró importante el uso de aguas residuales para este estudio debido a su composición o naturaleza. Las aguas servidas consisten de dos componentes: un efluente líquido y un constituyente sólido en el que se asocian diferentes tipos de materiales particulados como sedimentos de residuos biológicos, lodo y otras sustancias. A este tipo de material se asocian microorganismos como bacterias, hongos y virus, los cuales tienen como sustrato los contenidos de este tipo de aguas (19).

Debido a que, por el grado de contaminación que presentan, en las aguas residuales se encuentra gran cantidad de bacterias de diferentes especies y se espera encontrar también los bacteriófagos que infectan estas mismas bacterias, ya que estos últimos constituyen un control biológico para las colonias bacterianas. La presencia de bacteriófagos en aguas residuales se explica, además, por el hecho de que en el agua dulce, que constituye su base primaria, la abundancia de bacteriófagos es de 10 a 20 veces mayor que la de la cédula hospedera (20). Aunque en la actualidad en la región de estudio no se cuenta con gran experiencia en las metodologías de aislamiento y no se han reportado obtenciones de bacteriófagos a partir de aguas negras, por lo anterior se propone como objetivo estandarizar 
una técnica para el aislamiento de bacteriófagos específicos para E. coli DH5a a partir de aguas residuales.

\section{MATERIALES Y METODOS}

Obtención de bacteriófagos. Para alcanzar los objetivos propuestos se desarrolló la siguiente metodología, se utilizaron 5 litros de agua residual para la obtención de bacteriófagos. Se realizaron 7 repeticiones de cada uno de los experimentos, siguiendo lo sugerido por varios autores $(16,21,22)$. Esto se realizó para brindar una mayor confiabilidad de los resultados en cuanto a la estandarización de la técnica para el aislamiento de bacteriófagos a partir de aguas residuales.

Sitio de estudio y toma de la muestra. Se tomó un litro de agua residual de un vertedero de aguas residuales del municipio de Salento, Quindío, utilizando una botella de plástico nueva y limpia. Se almacenó a $4^{\circ} \mathrm{C}$ en una nevera de poliestireno expandido y luego se transportó al laboratorio para su procesamiento.

Aislamiento de bacteriófagos. Una vez en el laboratorio, se llevó el litro de agua residual a centrifugación a 5100 x g a $4^{\circ} \mathrm{C}$ durante 30 minutos, en una centrifuga de Marca IEC modelo B-22 M 34961048. Concluido este tiempo, el sobrenadante se transfirió a un frasco plástico de $1.5 \mathrm{~L}$. El precipitado se resuspendió en $1 \mathrm{~mL}$ de extracto de carne y $1 \mathrm{~mL}$ de cloroformo y se almacenó en tubos de vidrio de $10 \mathrm{~mL}$. Esta solución se homogenizó utilizando un vórtex durante $3 \mathrm{~min}$ y se centrifugó a $1050 \times \mathrm{g}$ a $4^{\circ} \mathrm{C}$ durante 30 minutos. Una vez finalizado este ciclo, se colectó el sobrenadante, el cual se depositó en el frasco de plástico de $1.5 \mathrm{~L}$ que contenía el sobrenadante de la primera centrifugación. El precipitado restante se resuspendió en $1 \mathrm{~mL}$ de extracto de carne y se sometió nuevamente a centrifugación bajo las mismas condiciones antes mencionadas. Finalmente se tomó de esta etapa el sobrenadante y se almacenó en el frasco de plástico mencionado al inicio de este protocolo. Luego, al total de muestra almacenada en el frasco de $1.5 \mathrm{~L}$, se le agregaron $17.5 \mathrm{~g}$ de cloruro de sodio $(\mathrm{NaCl})$ y $80 \mathrm{~g}$ de polietilenglicol (PEG) y se dejó en reposo, almacenado a una temperatura de $4^{\circ} \mathrm{C}$ durante 24 horas.

Posteriormente se centrifugó esta solución a $5100 \times \mathrm{g}$ a $4^{\circ} \mathrm{C}$ durante 45 minutos. Al finalizar este paso se descartó el sobrenadante y el precipitado se resuspendió con $1 \mathrm{~mL}$ de solución amortiguadora de fosfato al 1x (PBS). Luego, para lavar el frasco donde se encontró el precipitado se pipeteó varias veces $y$, finalmente, se obtuvieron aproximadamente $6 \mathrm{~mL}$ de la muestra, la cual se almacenó en tubos de vidrio y se le agregó medio volumen de cloroformo ( $50 \%$ de la muestra y $50 \%$ de cloroformo).

Esta solución se homogenizó utilizando un Vórtex a una velocidad media durante 3 minutos y se centrifugó a $1050 \mathrm{X} \mathrm{g}$ a $4^{\circ} \mathrm{C}$ durante 30 minutos. Después se coleccionó el sobrenadante en un tubo Falco de $15 \mathrm{ml}$ y al precipitado resultante se le agregaron $2 \mathrm{~mL}$ de extracto de carne al $3 \%$ y se centrifugó nuevamente a $1050 \times \mathrm{g}$ a $4^{\circ} \mathrm{C}$ durante 30 minutos. Luego se coleccionó el sobrenadante junto con la muestra mencionada en el paso anterior. Esta muestra se distribuyó en viales almacenando $2 \mathrm{~mL}$ del sobrenadante y se almacenó a $4^{\circ} \mathrm{C}$.

Tratamiento para limpieza de las muestras final que contienen los bacteriófagos. Se tomaron $1300 \mu \mathrm{L}$ de la muestra que se obtuvo en la fase de aislamiento y se almacenaron en un vial. Se les agregaron $100 \mu \mathrm{L}$ de cloroformo, se agitaron por un tiempo de $3 \mathrm{~min}$ en el Vórtex a velocidad media y, posteriormente, se centrifugaron a 2500 x g durante $10 \mathrm{~min}$. Una vez finalizada esta etapa se llevaron a la cabina de flujo laminar y el sobrenadante resultante se distribuyó en cantidades de $200 \mu \mathrm{L}$ en viales y luego se almacenó a una temperatura de $-70^{\circ} \mathrm{C}$.

Cultivo de la bacteria anfitrión (E. coli DH5a). Se preparó como medio de cultivo para las bacterias caldo tripticasa de soya (CST). Se tomaron $5 \mathrm{~mL}$ de este, y se almacenaron en un tubo cónico de $15 \mathrm{~mL}$, se les agregaron $100 \mu \mathrm{L}$ de una solución de $E$. coli DH5a bacteria huésped, y se dejó crecer durante 24 horas en movimiento en un agitador orbital a 70 r.p.m. Posterior a esto, se realizó una resiembra. Se tomó $1 \mathrm{~mL}$ de las bacterias antes cultivadas y se inoculó en un tubo con $30 \mathrm{~mL}$ de caldo tripticasa de soya (CST) y se dejó crecer durante 4 horas.

Preparación del inóculo viral en diluciones seriadas. Se tomaron 14 viales de $1.5 \mathrm{~mL}$ (Eppendorf), de los cuales 7 se utilizaron para el experimento con el bacteriófago control (Fago T4) donado por el Dr. KendDuor de la Universidad de California y 7 para la muestra de bacteriófagos obtenida a partir de aguas residuales mediante el protocolo antes descrito. Se marcó cada uno de los viales indicando su respectiva dilución. Luego, a cada uno se le agregaron $900 \mu \mathrm{L}$ de caldo tripticasa de soya. A continuación, se inocularon en el vial \#1 $100 \mu \mathrm{L}$ de la muestra que contiene los bacteriófagos. Se mezcló utilizando un Vórtex por un tiempo de 1 
min. Luego se tomaron de esta primera dilución $100 \mu \mathrm{L}$ de su contenido y se agregaron al vial \# 2 , realizándose el mismo procedimiento antes mencionado, y de esta forma se realizaron de forma sucesiva las 7 diluciones dobles seriadas. De igual forma se realizó para la solución que contenía el bacteriófago T4, el cual se tuvo en cuenta como control positivo en este protocolo.

Fase de infección con bacteriófagos a las células bacterianas. Se tomaron 14 viales (Eppendorf) y se marcó doblemente cada vial respectivamente desde -1 hasta -7 , representando cada una de las diluciones realizadas. Luego, a cada uno de los viales se le colectaron $500 \mu \mathrm{L}$ de las diluciones realizadas. Estos contenidos se almacenaron en los tubos previamente marcados y a cada uno de ellos se les agregaron $100 \mu \mathrm{L}$ de las bacterias repicadas con un tiempo de crecimiento de 4 horas. Al mezclarse los bacteriófagos con las bacterias se esperó un tiempo aproximado de 4 minutos, lo cual facilitó de cierta manera que muchos de los bacteriófagos infectaran gran cantidad de bacterias en esta siembra.

Siembra de inóculos virales y bacterianos. Se tomaron 14 tubos cónicos de $15 \mathrm{~mL}$, se marcaron doblemente los tubos de -1 hasta -7 , se le agregó a cada uno de ellos agar suave tripticasa de soya previamente esterilizada y en solución. Se llevaron al baño María, en el cual se estabilizó su temperatura entre un rango de $45^{\circ} \mathrm{C}$ y $50^{\circ} \mathrm{C}$. Luego se tomaron los inóculos previamente preparados en los viales de 1.5 $\mu \mathrm{L}$ y se vertieron en el agar suave tripticasa de soya. Se mezcló ligeramente, garantizando una buena distribución del inóculo en esta siembra. Se vertió el contenido total a cajas de Petri previamente marcadas, siguiendo el orden de cada una de las diluciones. Se dejaron solidificar $y$, posterior a esto, se les agregó una segunda capa de agar siguiendo las modificaciones para la siembra (21). Una vez solidificado todo el contenido de cada caja se sellaron con papel celofán o parafilm para evitar contaminación y se llevaron a la incubadora microbiológica durante $24 \mathrm{~h}$ a $37^{\circ} \mathrm{C}$.

Titulación de bacteriófagos. Se tomó cada una de las cajas de Petri y se registró en la bitácora de acuerdo con su número de dilución. A cada una se le determinó el número de unidades formadoras de placa (UFP), una vez determinado este, se multiplicó por el inverso de la dilución, para así saber el contenido de bacteriófagos en cada una de las muestras respectivamente (21).
Análisis estadístico. Se tomó como modelo estadístico el análisis de interacción con dos factores. El análisis de ANOVA se realizó mediante el software estadístico Statgraphics Centurion XV. Se compararon los resultados entre los tratamientos control (FT4) y experimental (Bacteriófagos a partir de aguas residuales).

\section{RESULTADOS}

En el conteo y observación de las UFP, que se realizaron al tratamiento control con el bacteriófago T4 y al tratamiento experimental de los bacteriófagos obtenidos a partir de aguas residuales, se encontró que no existe una diferencia significativa $(p>0.05)$ entre los tratamientos, (Figura 1). Sin embargo, aunque la diferencia no fue marcada, en la lectura de placas del tratamiento control se observó un mayor número de estas. En los conteos realizados se cuantificó un mayor número de UFP dentro del experimento control que dentro de la prueba experimental.

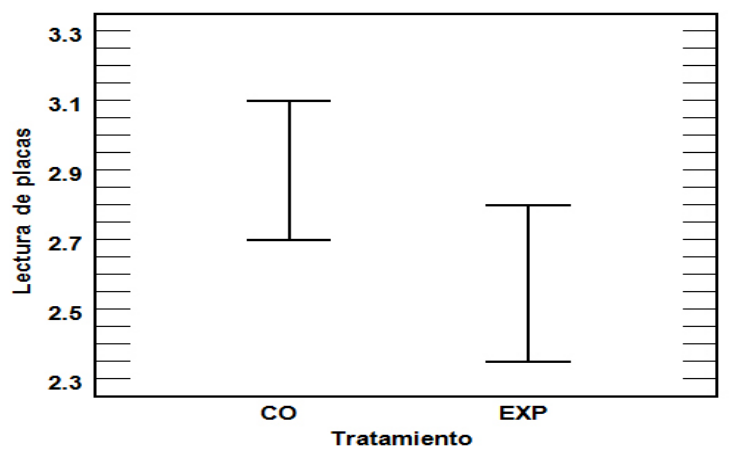

Figura 1. Análisis de interacción de dos factores para la variación en los tratamientos control (FT4) y experimental (Bacteriófagos obtenidos a partir de aguas residuales) respecto a la lectura o titulación de placas (UFP) o calvas.

En la estandarización del protocolo se encontró que algunas variables, como la temperatura, afectan de manera directa la fase de infección viral, y por ende la titulación de los bacteriófagos. De las diluciones seriadas que se realizaron se tomó cada uno de los volúmenes del inóculo que se usó como muestra, tanto para la prueba control, como para la prueba experimental. Estas diluciones facilitaron las lecturas de las placas de lisis observadas. Se observó que, al realizar los ensayos experimentales en el laboratorio, se debe tener en cuenta no exceder las diluciones en una cifra superior a $1 \times 10^{-6}$, ya que en el momento de cuantificar los bacteriófagos no existen diferencias significativas entre las 
diluciones, a medida que estas se amplían a partir de este punto de dilución (Figura 2). Los resultados que se obtuvieron al comparar las medias de cada una de las diluciones entre la prueba control y la experimental presentaron un comportamiento igual a lo observado de forma cuantitativa en el momento en que se contaron las UFP.

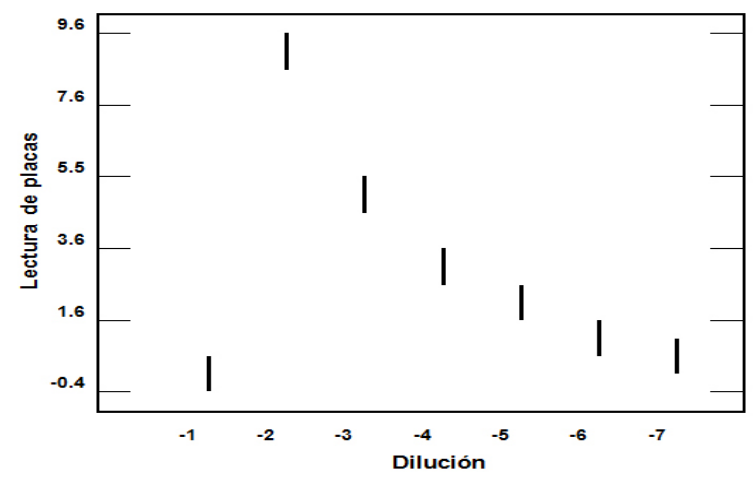

Figura 2. Análisis de interacción de dos factores para la variación de las diluciones seriadas realizadas en cada uno de los experimentos de detección de bacteriófagos respecto a la lectura o titulación de placas (UFP) o calvas.

El comportamiento resultante del modelo estadístico utilizado mostró también que entre cada una de las diluciones realizadas desde $1 \times 10^{-}$ 2 hasta $1 \times 10^{-6}$ existe diferencia significativa ( $p>0.005$; Figura 2). Partiendo de este análisis estadístico se deduce hasta qué punto se deben extender las diluciones, una vez se ha iniciado un ensayo con bacteriófagos obtenidos a partir de aguas servidas específicos para $E$. coli DH5a.

La lectura de placas que se realizó en cada una de las diluciones hechas para el tratamiento control y para el tratamiento experimental mostró que entre la dilución $1 \times 10^{-1}$ de ambos tratamientos no existió diferencia significativa ( $p>0.005$; Figura 3 ), en las diferentes repeticiones que se realizaron para determinar la confiabilidad en la estandarización de este protocolo en esta dilución. Los datos de la titulación de los bacteriófagos aislados presentaron una desviación de la tendencia al realizar el análisis de la figura 3 , donde se observan diferencias entre las diluciones realizadas y la lectura de placas, tanto para el tratamiento control, como para el tratamiento experimental (Figura 3).

Entre los resultados que se obtuvieron se observaron UFP de forma circular (Figura 4), claras y de diferente tamaño y otras de formas

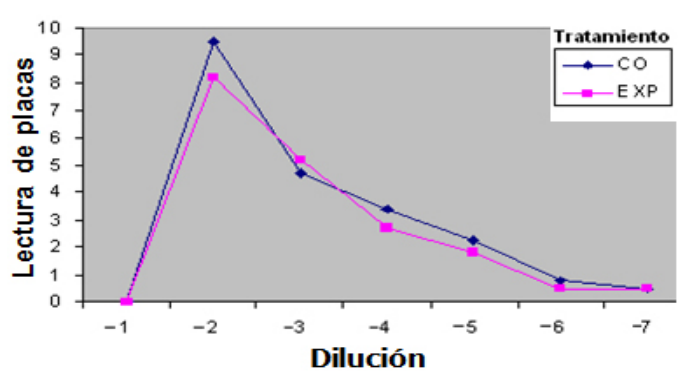

Figura 3. Análisis de interacción de dos factores para la variación de las diluciones seriadas realizadas en cada uno de los experimentos de detección de bacteriófagos, tanto para el tratamiento control como para el tratamiento experimental, respecto a la titulación o cuantificación de bacteriófagos que se realizó.

no definidas o confluentes. En la gran mayoría de ensayos realizados se pudo observar de manera clara gran cantidad de unidades formadoras de placa (UFP) (Figuras 5 y 6 ).

Dentro de los cultivos de la dilución $1 \times 10^{-1}$ se observaron muchas UFP unidas entre sí y pocas claras y diferenciadas una de otra. Estas se observaron en diferentes puntos, los cuales no presentaron las características esperadas de la lisis celular en esta dilución por la gran cantidad de bacteriófagos que se debe encontrar en esta. Debido a esto, al llevar los datos al modelo estadístico donde se realizó el análisis de interacción con dos factores, está presente una inconsistencia, la cual se puede inferir como un error al momento de la toma de datos en la titulación fágica. Sin embargo, la aclaración antedicha de los datos encontrados y de lo que

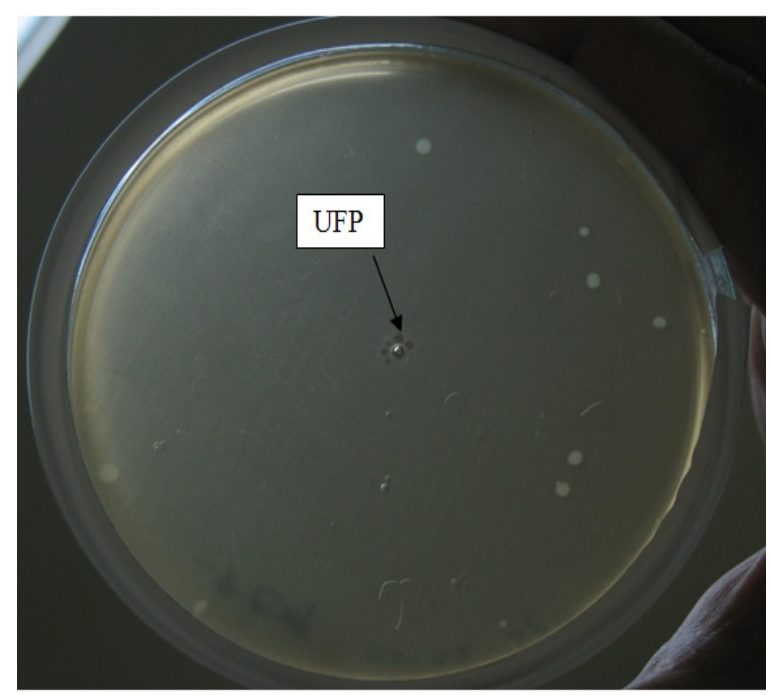

Figura 4. Observación de lisis generada por los bacteriófagos obtenidos a partir de aguas residuales en medios de cultivo de E. coli. DH5a. 


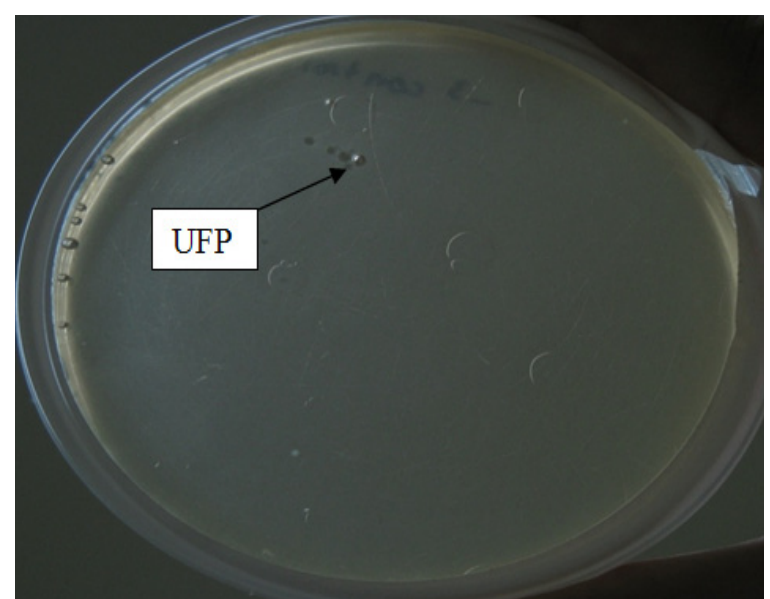

Figura 5. Observación de unidades formadoras de placa (UFP) con forma circular y altamente diferenciadas una de otra.

se observó en la primera dilución aclara cada uno de estos interrogantes $y$, por ende, facilita la comprensión del análisis en este caso (Figura 3).

Los resultados del tratamiento control mostraron, en lo general, valores por encima del tratamiento experimental. Esto se presentó ya que en la mayoría de las repeticiones de los ensayos que se realizaron se encontró un mayor número de placas dentro del tratamiento control, cuyas características presentaron formas redondeadas y aisladas una de otra. Cuando se observaron algunas de ellas fusionadas y de forma irregular dentro de las primeras diluciones $\left(1 \times 10^{-1}, 1 \times 10^{-2}, 1 \times 10^{-3}\right)$, para la discusión se consideraron sus características y cada una de las formas en las que se presentaron ensayo tras ensayo. Además, se encontró una diferencia significativa en cuanto a la lectura de placas entre el tratamiento control y el tratamiento experimental en la dilución $1 \times 10^{-3}$, como se muestra en la figura 3, en la cual se presenta un mayor número de UFP en el tratamiento experimental que en el tratamiento control.

De igual forma, siempre se observó un mayor número de UFP en el control, tanto en el experimento, como en las diferentes repeticiones que se realizaron para confirmar la reproducibilidad y especificidad de la técnica que se estandarizó. Se encontraron las diluciones adecuadas donde se encuentra la sensibilidad de la técnica $y$, por ende, el factor de dilución hasta donde se deben extender los diferentes experimentos realizados bajo este protocolo. De acuerdo con las observaciones que se realizaron, se describe claramente en la figura 3 que las diluciones que se deben realizar para determinar la sensibilidad que se encontró en este experimento están dentro de $1 \times 10^{-1}$ y

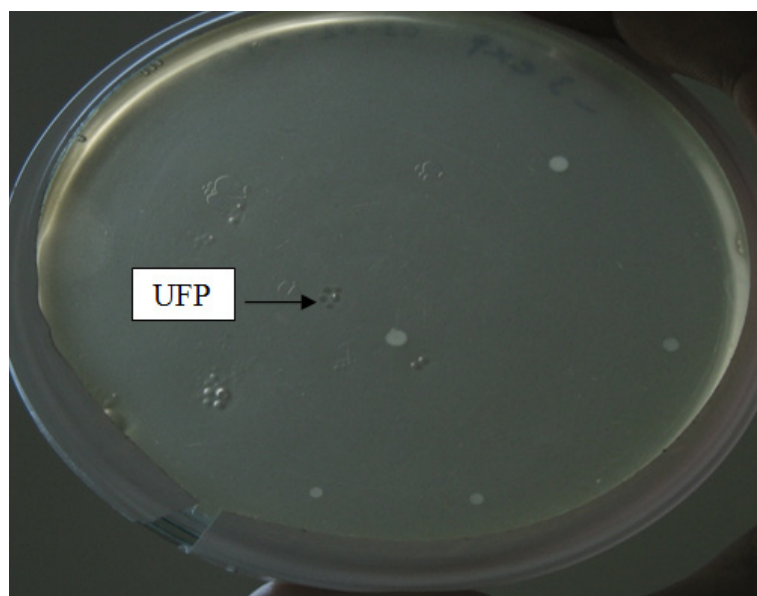

Figura 6. Observación de unidades formadoras de placa(UFP) en una monocapa de $E$. coli DH5a, producto de la acción lítica de bacteriófagos obtenidos a partir de aguas residuales.

$1 \times 10^{-6}$, ya que se ampliaron y se encontró que no existe diferencia significativa entre ambas pruebas. Con esto se observó, además, que las características de las UFP y su titulo fágico eran muy similares. Dentro del trabajo de laboratorio se extendieron en algunos experimentos estas diluciones y se encontró que, en el momento en que se obtuvo el titulo fágico, se presentaron inconsistencias dentro del modelo matemático. Con lo que se encontró, se determinó como útil detallar las 6 primeras diluciones como óptimas para evidenciar la sensibilidad de la prueba o protocolo estandarizado para el aislamiento de bacteriófagos a partir de aguas servidas.

\section{DISCUSIÓN}

En las observaciones y conteos que se realizaron al tratamiento control se determinó que éste obedece a las características propias de la muestra control, ya que, a medida que se encuentra el bacteriófago purificado, se espera una mayor acción lítica a las bacterias que se tienen como anfitrión, en este caso E. coli DH5a. Tanto la cantidad de unidades formadoras de placa(UFP), como la pureza en que encuentren los bacteriófagos, están directamente relacionadas con el tipo de bacteriófago que se utilice en la prueba control. Existen otros factores entre los que se cuenta la alta densidad bacteriana (20). Esto quiere decir que, a mayor densidad del hospedero, mayor es la oportunidad de infección $y$, por ende, mayor número de unidades formadoras de placa (UFP). Además, esto se relaciona con otro factor 0 , más bien, otra característica biológica, que es la alta especificidad que poseen los bacteriófagos frente a las células diana que ellos infectan. La característica de especificidad que tienen los 
bacteriófagos depende tanto de las propiedades de la cepa del bacteriófago, como de los receptores específicos situados en la superficie de la bacteria, debido a que la multiplicación de los bacteriófagos ocurre solo cuando el organismo tipo y el bacteriófago coinciden (23).

De acuerdo con las observaciones realizadas a los cultivos bacterianos, se encontró la formación de unidades formadoras de placa (UFP) de forma clara y diferenciada, facilitando una mayor precisión en la cuantificación o titulación fágica para los diferentes experimentos realizados. El hecho de que se presente un comportamiento de este tipo, facilita la observación de la lisis que se presenta en cada uno de los cultivos bacterianos y, a su vez, facilita el proceso de titulación de bacteriófagos, no solo en experimentos de este tipo, sino en otros como son la caracterización de algunas bacterias a través de bacteriófagos y algunas relaciones biológicas que existen entre ellos (22).

Los conteos que se realizaron en cada uno de los cultivos bacterianos infectados por los bacteriófagos, presentaron diferentes títulos fágicos, inclusive algunas diferencias significativas entre la muestra control y la muestra experimental, especialmente en la primera dilución. Esto se dio debido a que el conteo de las unidades formadoras de placa (UFP) que se realizó en la primera dilución es muy bajo, debido a que, por la gran concentración de bacteriófagos en esta dilución, las Unidades formadoras de placa (UFP) se mezclaron, lo cual hizo que se observaran unas pocas UFP diferenciadas en los cultivos, generadas por la abundante acción lítica en las monocapas bacterianas de $E$. coli $\mathrm{DH} 5 \mathrm{a}$.

Para cada uno de los conteos de unidades formadoras de placa (UFP) se determinaron las características o formas de las UFP para cada cultivo, tanto en el tratamiento experimental, como en el tratamiento control, detallando con esto la titulación fágica como un método para determinar la concentración de bacteriófagos contenidos en cada uno de los ensayos realizados. La observación de la forma y disposición de las placas de lisis no solo permite la cuantificación, sino la determinación de la relación bacteriófago-bacteria (24). Se considera que las diferencias en las placas de lisis implica la presencia de diferentes tipos de bacteriófagos infectantes dentro de una muestra (25). Aunque este no es precisamente el caso del tratamiento control, ya que este es un bacteriófago ya purificado y caracterizado previamente, las particularidades de amorfía que se presenta en las UFP que se observaron con el FT4 o bacteriófago control, se dan por las altas concentraciones de bacteriófagos que infectan y reinfectan las células bacterianas, haciendo que se tornen de una manera no definida las calvas que se dan por la acción lítica de los bacteriófagos en las bacterias. Sin embargo, lo planteado por Talledo et al(25) sí se ajusta a lo obtenido en el tratamiento experimental, en el cual se observaron y se titularon UFP con unas formas inconsistentes, pero aisladas una de otra, ya que una condición básica dentro de la titulación de bacteriófagos en cultivos sembrados en medio sólidos es que las unidades formadoras de placa(UFP) no necesitan ser precisamente de una forma circular perfecta.

El hecho de que se presente una mayor cantidad de unidades formadoras de placa (UFP) en una dilución especifica permite inferir que los bacteriófagos que se titularon según su efecto lítico en esta dilución presentaron una mayor tasa de infección a las células bacterianas que crecieron en este experimento y, por ende, una mayor tasa de replicación de bacteriófagos.

El aumento de las unidades formadoras de placa (UFP) en esta dilución se da debido a múltiples factores como son el número de bacterias que crecieron, el cual debe haber sido abundante para que estas bacterias hayan sido infectadas y, por consiguiente, haberse observado una mayor cantidad de unidades formadoras de placa UFP. Otro de los factores que están relacionados con este resultado es la fase logarítmica en la que se deben haber encontrado las bacterias para ser infectadas por los bacteriófagos, ya que si las bacterias se encuentran en el inicio de la fase de latencia o finalización de la fase logarítmica, el porcentaje de infección disminuye y, por ende, disminuye la aparición de unidades formadoras de placa(UFP). Por lo general, los resultados de las titulaciones fágicas siempre serán variables, ya que las condiciones de cada uno de los experimentos son complicadas, lo cual hace que la reproducibilidad de las técnicas de aislamiento de bacteriófagos presente dificultades. Además, se debe tener en cuenta que los resultados de la titulación pueden variar entre un ensayo y otro, por la resistencia que se puede generar por parte de las bacterias a la infección por bacteriófagos (21).

Se plantea que para la titulación de bacteriófagos, tanto en razón de UFP por $\mathrm{mL}$, como de unidades formadoras de placa por caja de Petri, se debe tener en cuenta el grado de amplificación de los bacteriófagos y, además, las técnicas de limpieza de cada una de las muestras de bacteriófagos aislados (16). Otro de los factores 
de gran atención para la titulación son las diferentes diluciones realizadas en cada uno de los experimentos, ya que si se tiene un bacteriófago repetidamente amplificado en cultivos de bacterias en medios líquidos, se deben extender las diluciones a títulos de $1 \times 10^{-6}, 1 \times 10^{-8}, 1 \times 10-$ 10 y $1 \times 10^{-12}$, caso que se presentó en el trabajo de aislamiento de bacteriófagos específicos para $R$. sphaeroidesa partir de aguas, el cual facilitó el proceso de titulación realizado por este mismo autor.

Al relacionar el protocolo de estandarización de aislamiento de bacteriófagos a partir de aguas residuales, se menciona que se tuvieron en cuenta factores como las repetidas amplificaciones de bacteriófagos y, además, el tipo de solventes que se utilizaron para la limpieza de cada una de las muestras de bacteriófagos aislados. Aunque en esta fase no se afectó la cuantificación de unidades formadoras de placa (UFP) por la utilización del cloroformo como solvente orgánico, se ha reportado en la literatura, a manera de recomendación, el uso de éter como un solvente orgánico adecuado para este tipo de protocolo, el cual no solo limpia las muestras sino que contribuye como evidencia primaria dentro de la caracterización de bacteriófagos (16).

\section{REFERENCIAS}

1. Sobsey M. Methods for recovering viruses from shellfish, seawater and sediments. En: Methods for recovering viruses in the environments. Boca de Ratón, FL: CRC Press, 1987:77-108.

2. Luria $E$, Delbrück $M$, Anderson F. Electron microscope studies of bacterial viruses. ] Bact 1943; 46:57-77.

3. Tetárt F, Desplats $\mathrm{C}$, Kutateladze M, Monod $\mathrm{C}$, Ackermann $\mathrm{H}$, Krich $\mathrm{H}$. Phylogeny of the major head and tail genens of the wide ranging T4Type bacteriophages. J Bact $2001 ; 183: 358-66$.

4. Smith $H$, Huggins $M$, Shaw K. The control of experimental Escherichia coli diarrhoea in calves by means of bacteriophages. J Gen Microbiol 1987; 133: 1111- 26.

5. Lindqvist $H$. Bacteriophage and gene transfer. APMIS 1998; (Suppl 84):15-8.

6. Sonea S. Bacterial viruses, prophage, and plasmids, reconsidered. Ann N Y AcadSci 1987; 503:251-60.

7. Hernández A. Aislamiento, caracterización y detección precoz de bacteriófagos de Streptococcus thermophilus en la industria Láctea.[Tesis doctorado en ciencias]. Oviedo: Universidad de Oviedo; 2007.

8. Ralston D, Krueger A. The Isolation of a Staphylococcal phage variant susceptible to an unusual host control. J Gen Physiol $1954 ; 37: 685-36$.
9. Meyers C, Walter E, Green L. Isolation of a bacteriophage specific for a Lactobacillus Casei from human oral material. J Dent Res 1958; 37(1):175-179.

10. Johnson K, Chow C, Lyric R, Caeseele $\mathrm{L}$. Isolation and characterization of $\mathrm{a}$ bacteriophage for Thiobacillus novellus. ] Virol 1973; 12:1160-1163.

11. Budzik J. Phage Isolation and investigation. DUJS 2000; 3:37-43.

12. García E, López R. Los bacteriófagos y sus productos génicos como agentes microbianos. Revista Esp Quimioterap 2002; 15:306-312.

13. Ronda C, Vasquez M, López R. Los bacteriófagos Como herramienta para combatir infecciones en acuicultura. Revista AquaTIC 2003; 8:3-10.

14. Westwater C, Pasman L, Schofield D, Werner P, Dolan J, Schmidt M, Norris J. Use of genetically engineered phage to deliver antimicrobial agents to bacteria: an alternative therapy for treatment of bacterial infections. Antimicrob Agents Chemother 2003; 47:1301-1307.

15. Sulakvelidze A. Phage therapy: an attractive option for dealing with antibiotic resistant bacterial infections. Drug Discov Today 2005; 10:807-9.

16. Rojas M. Bacteriófagos específicos para Rhadobacter Sphaeroides: Aislamiento, caracterización y potenciales transductores[Tesis doctorado en ciencias]. Oviedo: Universidad de Oviedo; 2005. 
17. Wagenaar J, Van Bergen $M$, Mueller $M$, Wassenaar T, Carlton R. Phage therapy reduces Campylobacter jejuni colonization in broilers. Vet Microbio 2005; 109:275-283.

18. BruttinA,Brussow H. Human volunteers receiving Escherichia coli phage T4 orally: a safety test of phage therapy. Antimicrob Agents Chemother 2005; 49:2874-2882.

19. Reynolds, K. Tratamiento de aguas residuales en Latinoamérica. Agua Latinoamerica 2002; 12:1-4.

20. Fuhrman J, Schwalbach M. Viral influence on aquatic bacterial communities. Biol bull 2003; 204:192-5.

21. Talledo M, Gutierrez S, Merino F, Rojas N. Detection, Quantification and morfological characterization of Vibrio cholerae indicator bacteriofagues. Rev Peru Bio 1998; 5:12-16.
22. Talledo $M$, Gutierrez S, Merino F. Una alternativa para la deteccion de Vibrio Cholerae en aguas. Rev Peru Epidemio $1994 ; 7: 30-34$.

23. Dulbecco $R$, Ginsberg $H$. Parte 5: Virología.En: Tratado de Microbiología. 3ra. Edición. México: Salvat Mexicana de Ediciones S.A, 1990.

24. Ackermann W. Bacteriophage observations and evolution. J Microbiol 2003; 154:245-251.

25. Talledo M, Gutiérrez S, Merino F, Rojas N. Detección, cuantificación y caracterización morfológica de bacteriófagos indicadores de Vibrio cholerae. Revista Peruana de Biología 1998;5(2). URL Disponible en: http://sisbib.unmsm.edu.pe/BVRevistas/ biologia/v05_n2/vibrioc.htm. 